\title{
LA MITOLOGÍA CLÁSICA EN LA OBRA DE FR. MARTÍN SARMIENTO
}

\author{
Por \\ FERNANDO GARCÍA ROMERO
}

\section{RESUMEN}

Nos hemos propuesto realizar un estudio de las referencias que encontramos en los escritos de Fr. Martín Sarmiento a propósito de la Antigüedad grecolatina y en particular de la Mitología. Esas referencias se hallan especialmente en relación con las reflexiones de Fray Martín sobre cuestiones lingüísticas (etimológicas en buena parte), literarias, históricas, pedagógicas, botánicas y sociopolíticas, y aparecen tanto en sus obras eruditas como en sus epístolas. Con frecuencia esas alusiones se refieren a sus comentarios a propósito de la historia antigua, la lengua y las costumbres de Galicia.

\section{PALABRAS CLAVE}

Martín Sarmiento, Mitología Clásica, Antigüedad Clásica, Filología, Etimología, Hispania Antigua, Galicia Antigua.

\section{ABSTRACT}

We have studied the references we have found in the works of Fr. Martín Sarmiento about the Classical World and specially about Classical

«CUADERNOS DE ESTUDIOS GALLEGOS», Tomo XLVIII, Fascículo 114, Santiago 2001. 
Mythology. Those references have relationship above all with Fray Martin's commentaries about linguistics (specially etymology), literature, history, pedagogy, botany and social and political questions, and can be found both in his erudite works and in his epistles. Those mentions are often found in his commentaries about Galicia's ancient history, language and folklore.

\section{KEYWORDS}

Martín Sarmiento, Classical Mythology, Classical World, Philology, Etymology, Ancient Hispania, Ancient Galicia.

Entre los hombres que sin duda merecieron el título de sabios en el siglo XVIII español, el benedictino Fray Martín Sarmiento (nacido en Villafranca del Bierzo en 1695 y muerto en Madrid en 1772) ocupa un lugar especial ${ }^{1}$. Pasó la mayor parte de su vida en el madrileño convento de San Martín, y en su celda estableció una espléndida biblioteca particular (su colección de autores griegos apenas tuvo rivales en la España de su siglo) y su celda fue también lugar habitual de reunión de los más destacados intelectuales de su tiempo. Pero Sarmiento fue también un hombre contradictorio. Lector y escritor incansable, dejó inédita casi toda su excepcional obra, alegando: «yo sólo escribo para mi instrucción y para complacer a cuatro amigos... España no está para imprimir, ni aún para saber, sino cada uno para sí mismo... El mayor peligro de la tranquilidad humana es decir lo que se piensa ${ }^{2}$; decir lo contrario de lo que se piensa es ignominia de la racionalidad y de la sociedad humana. Pues

${ }^{1}$ Sobre su figura, véase J.L. ALBORG, Historia de la literatura española. Siglo XVIII, Madrid 1997², III 192-205; X. FILGUEIRA, Fray Martín Sarmiento, La Coruña 1994; J.L. PENSADO, Fray Martín Sarmiento, testigo de su siglo, Salamanca 1995². Cf. «Guía bibliográfica para el estudio de Fray Martín Sarmiento», Cuadernos de Estudios Gallegos 27 (1972), pp. 369-379.

${ }^{2} \mathrm{Al}$ hacer tal afirmación, probablemente tuviera en mente Sarmiento las polémicas que suscitaban los escritos de su buen amigo Feijoo. 
¿qué remedio? El que yo he escogido. Es vivir retirado en un rincón; abstenerme de todo comercio mundano, político, literario y epistolar; y vivir sólo para Dios, para mí y para los amigos». Curiosa contradicción entre esta postura «egoísta» de renuncia al magisterio y la profundidad de las preocupaciones sociales y pedagógicas que manifiestan constantemente sus escritos.

Esta vida voluntariamente retirada que llevó Sarmiento no impidió que fuera saludado por el propio Feijoo como el hombre más sabio de su tiempo: «Mi religión tiene un sujeto que en edad de 35 años es un milagro de erudición... En cualquier materia que se toque da tan prontas, tan individuadas las noticias, que no parece que se oyen de su boca, sino que se leen en los mismos autores de donde las bebió». Y más de siglo y medio después Azorín (Alma castellana, 1600-1800, publicada en 1900), que apenas pudo haber leído unas pocas obras suyas, lo considera «la figura más vigorosa de su tiempo», y califica su Discurso sobre el método que debía guardarse en la educación de la primera juventud como «una de las más geniales obras de nuestra literatura» ${ }^{3}$.

Sarmiento, como hijo de su tiempo, fue hombre de una curiosidad intelectual insaciable, que no conocía límites ni especializaciones, y de una enorme capacidad de trabajo, cualidades ambas que lo llevaron a interesarse por las más variadas disciplinas ${ }^{4}$; pero hay tres campos del saber que cultivó especialmente y acerca de los cuales nos dejó algunas obras magistrales, donde se exponen ideas que en ocasiones se adelantan en varias décadas, e incluso en un siglo, a su tiempo. En primer lugar, las ciencias naturales y en especial la Botánica. En segundo lugar, la educación ${ }^{5}$;

\footnotetext{
${ }^{3}$ Cf. J.L. PENSADO, Fray Martín Sarmiento, testigo de su siglo, p. 11.

${ }^{4}$ Son muy ilustrativos al respecto los volúmenes colectivos Estudos adicados a Fr. Martín Sarmiento: artigos tirados dos Cuadernos de estudios gallegos (1945-1982), Santiago de Compostela 1995, y O Padre Sarmiento e o seu tempo. Actas do Congreso Internacional do Tricentenario de Fr. Martín Sarmiento (1695-1995), Santiago de Compostela 1997, 2 vol. Véase también el estudio introductorio de R. MARIÑO PAZ, en su edición de la obra de Fray Martín Coloquio de vintecatro galegos rústicos, Santiago de Compostela 1995, sobre todo pp. 9 ss.

${ }^{5}$ Véase P. ALLEGUE, La filosofia ilustrada de Fr. Martín Sarmiento, Tesis doctoral, Univ. Complutense de Madrid, 1990; A. GALINO, Tres hombres y un problema: Feijoo, Sarmiento y Jovellanos ante la educación moderna, Madrid 1953; J.L. PENSADO, La educación de la juventud de Fray Martín Sarmiento, Salamanca 1984.
} 
por supuesto, Sarmiento concibe el atraso español como un problema de incultura que sólo la educación puede remediar; por otro lado, sus ideas pedagógicas, modernísimas, se anticipan a Rousseau en diez años y en tres décadas a Pestalozzi; y en lo que al mundo de la Antigüedad clásica se refiere, Fray Martín propuso el primer plan de restauración oficial de la lengua gallega ${ }^{6}$, en el marco del cual pedía la creación de catedráticos de latín y griego en cada villa de Galicia «que enseñen [en gallego] la gramática y la lengua latina con un nuevo método, singular, fácil, breve y científico...en Galicia una sola escuela de aldea es más útil que una universidad». Y en tercer lugar, la Filología, una de sus grandes pasiones; sobre la importancia de sus trabajos en este terreno, baste un solo botón de muestra: "Sarmiento - comenta el romanista José Luis Pensado - se adelanta en muchos años a los grandes creadores de la Filología Románica... Es triste pensar que la lección de este maestro no haya sido aprovechada. Un discípulo fiel... hubiera dado a España la gloria de haber creado la ciencia que profesamos,... [sin haber tenido que] esperar a que la ciencia germánica nos volviera a poner en la senda correcta».

Puesto que, según comentamos más arriba, Sarmiento afirmaba escribir principalmente para sí mismo, no es de extrañar que su estilo carezca de grandes pretensiones literarias, puesto que quería «escribir como hablo». Eso explica que, a pesar de su extraordinario conocimiento del mundo antiguo, las alusiones mitológicas sean relativamente escasas en sus obras (no así las citas de autores antiguos, que son frecuentísimas y oportunas). En concreto en sus escritos filológicos y también a menudo en su epistolario esas referencias mitológicas suelen revestir un carácter erudito, para explicar el origen de algún uso o la etimología de alguna palabra. La etimología es, en efecto, una de las grandes pasiones de nuestro sabio, a partir de la idea, de clara raigambre clásica, de que es imposible el conocimiento preciso de las cosas sin penetrar en el origen de las palabras que las designan y conocer su significado original y las modificaciones que éste ha experimentado.

\footnotetext{
${ }^{6}$ En su Discurso apologético por el arte de rastrear las más oportunas etimologías, de Octubre de 1770. Véase X. FILGUEIRA, Frei Martín Sarmiento e a Galicia do seu tempo, La Coruña 1995.

${ }^{7}$ Fray Martín Sarmiento, sus ideas lingüisticas, Oviedo 1960, pp. 41-42.
} 
De toda su correspondencia publicada ${ }^{8}$, la carta que mayor número de alusiones mitológicas contiene es la carta $\mathrm{n}^{\circ} 137$, datada en Pontevedra el 3 de Junio de 1754 y dirigida a su amigo el Duque de Medina Sidonia. Comienza su epístola Sarmiento aludiendo a la reciente estancia del Duque en Aranjuez, y ello le da pie para comentar la etimología de ese topónimo, que los lingüistas consideran de origen prerromano, en concreto en relación con la voz aranz «espino» (que encontramos también en Aránzazu). Sarmiento observa, efectivamente, el parentesco existente entre Aranjuez y otros topónimos similares del País Vasco, pero establece para todos ellos un mismo origen latino, que él encuentra en la expresión ad aram Iovis («junto al altar de Júpiter»), y añade: «si allí... hubo en tiempos de los romanos un ara o altar dedicado a Júpiter, sería a Júpiter Tonante o a Júpiter Pluvio, para que no fulminase rayos ni despidiese truenos y tempestades, atendiendo a lo que el país está expuesto a esos terribles meteoros»).

Como caso excepcional en sus escritos, en esta epístola el Padre Sarmiento va engarzando alusiones mitológicas una tras otra por analogía, y así la mención de Júpiter Pluvio nos conduce al mito de Dánae, que nuestro autor, con sus buenas dosis de socarronería erudita, propone hipotéticamente relacionar con el origen que cree que tiene el nombre de Aranjuez. Sarmiento sabía de sobra que Iuppiter Pluvius o Pluvialis es el dios que envía la lluvia (como es evidente por ejemplo en Tibulo 1.7.26), pero en el texto que comentamos acepta otra explicación que se adecúa mejor a su broma erudita: «Bien sé que Júpiter no tanto se dijo Pluvio por las lluvias, cuanto por la estratagema que usó para visitar a Dánae, insinuándose por el tejado de la torre transformado en lluvia de oro. ¿Y qué sé yo si se tendría presente que el Tajo arranca con sus aguas de las minas comarcanas las arenas de oro que lleva? Sea por lo que fuere, y sea o haya sido el Júpiter que se quisiere, allí se veneraba a Júpiter como en otras muchas partes».

Toda la epístola rebosa de este fino y erudito humor de nuestro buen fraile, que dice haber bautizado con el nombre de Tempe su estancia pontevedresa por ser «un sitio tan delicioso que parece le tuvo presente

${ }^{8}$ Epistolario, disposto por X. FILGUEIRA e M ${ }^{\mathrm{a}}$ X. FORTES, Santiago de Compostela 1995.

«CUADERNOS DE ESTUDIOS GALLEGOS», Tomo XLVIII, Fascículo 114, Santiago 2001. 
Eliano cuando pintó el de Tesalia» ${ }^{9}$, y, puestos ya a establecer lazos de unión entre su Galicia y la antigua Grecia, sugiere con buen humor que tal vez la huidiza Dafne fuera gallega, por la abundancia de laureles que crecen en el país y lo esquivas que parecen ser las buenas mozas gallegas: «Sabe V.E. que Daphne significa laurel por la fábula de que la desdeñosa Daphne se transformó en laurel allá en tiempo de marras... ¿Y qué sé yo si en vista de la infinidad de laureles monstruosos que naturalmente nacen por este país sería gallega de coram vobis la dicha Daphne? Lo cierto es que siempre ha habido rollizas damas gallegas y espantadizas, que se esquivarían con el mismo Apolo aun siendo éste tan hermoso».

En fin, para concluir con las referencias mitológicas en la carta $\mathrm{n}^{\circ} 137$, tampoco faltan éstas en relación con otra de las grandes pasiones del Padre Sarmiento, la Botánica, ciencia y afición que cultivó a lo largo de toda su vida, sobre la que mucho escribió y que consideraba incluso fundamental para la educación, puesto que insistía en una de las ideas básicas de su sistema pedagógico, a saber, que todo lo que el niño ha de aprender en su temprana edad debe proceder de la observación directa del natural y ha de entrarle por los sentidos externos. Al final de la epístola que comentamos y en respuesta a una pregunta formulada por su destinatario, Sarmiento identifica «el árbol que Mariana llama Gerión» con el «dragón», «cuya lágrima o goma llaman sangre de dragón, por ser en todo de color de sangre, y esta droga es muy medicinal... Nace en América, en África, en Canarias, etc., y dicen que le hay en Ceuta. Así, no es inverosímil que le hubiese en Cádiz ${ }^{10}$ en tiempos antiguos»».

En otra epístola (la $n^{\circ} 171$ ) también dirigida al Duque de Medina Sidonia y fechada el 22 de Mayo de 1765, volvemos a encontrar vinculadas mitología y etimología, en este caso no en relación con el mundo de las plantas sino con el mundo de los animales, en concreto con las voces zura, zurana, zurita o zorita, que designan variedades de palomas silvestres y al respecto de las cuales comenta nuestro autor: «El origen de la voz es difícil. No será desatino afirmar que quedó en España el nombre

\footnotetext{
${ }^{9}$ En efecto, ELIANO, en Historias variadas 3.1, describe el valle de Tempe, en Tesalia, como un delicioso locus amoenus, y de hecho es un tópico de la literatura antigua, que ha pasado a la tradición literaria occidental (cf. E.R. CURTIUS, Literatura europea y Edad Media latina, Méjico-Madrid-Buenos Aires 1955, I 284-285).

${ }^{10}$ La patria del mítico Gerión.
} 
aludiendo al país de Siria, Suria o Soria, tres nombres del mismo país en donde hay infinitas y no se comen por estar dedicadas a Venus $\rangle^{11}$. En el diccionario etimológico de Corominas leemos que para la voz zura etc. no hay una etimología claramente establecida, y se ha propuesto un origen prerromano (vasco zuri «blanco»), un origen árabe (turi «silvestre») o puede ser simplemente una voz onomatopéyica, como supone Corominas.

De las epístolas personales pasamos a una obra excepcional, que sólo se publicó póstumamente, en 1775, las Memorias para la historia de la poesía y poetas españoles ${ }^{12}$, que hacen del Padre Sarmiento, como indica José Luis Pensado, un medievalista de primer orden. Este extenso tratado refleja no sólo la ingente cantidad y calidad de sus lecturas (literarias y eruditas, de obras editadas y de otras aún inéditas en los manuscritos de las bibliotecas), sino también su extraordinaria inteligencia y agudeza; la obra abarca desde los orígenes de la poesía española (y de la poesía en general) hasta los poetas del siglo XV, y está repleta de atinadísimas reflexiones filológicas e históricas ${ }^{13}$ sobre el origen y evolución de las lenguas y las literaturas de los pueblos que han habitado la península. Centrémonos en las referencias mitológicas que se encuentran en el tratado, todas las cuales tienen carácter erudito.

En primer lugar, en su disertación sobre la gran variedad de pueblos que han visitado y se han establecido en la Península Ibérica (54-56), alude Sarmiento a una tradición africana que nuestro autor conoce por la Guerra de Yugurta de Salustio (18.3) y que no documentan otras fuentes, según la cual Hércules murió en tierras de Hispania y a su muerte se dispersó el ejército que había traído consigo y que formaban soldados de muy diversas procedencias, entre los cuales medos, persas y armenios se

\footnotetext{
${ }^{11}$ Alude Sarmiento a continuación a la paloma cuja, «que es la columba cipria o de Chipre, aludiendo a Paphos», donde se ubicaba un célebre santuario de Afrodita. Recuérdese que la paloma es animal consagrado a esta diosa y que una de las etimologías que se ha propuesto para la palabra que en griego antiguo y moderno designa a la paloma doméstica, peristerá, la hace derivar del preverbio peri- y del nombre de la diosa mesopotámica identificable con Afrodita: «la que está alrededor de Istar»; la etimología más probable, sin embargo, es la que relaciona la palabra peristerá, con disimilación, con péleia «paloma salvaje», a partir de su color gris, que es lo que significa la raíz.

${ }^{12}$ Hemos utilizado la edición publicada en Buenos Aires 1942.

${ }^{13} \mathrm{Al}$ respecto, añádase a la bibliografía citada el libro de X. FILGUEIRA, Ideas $y$ sistema de la Historia en Fray Martín Sarmiento, Madrid 1981.
} 
trasladaron al norte de África; y se refiere igualmente Sarmiento a la dispersión de los griegos tras la toma de Troya, algunos de los cuales, según consta ya en los autores antiguos, llegaron a tierras de Iberia ${ }^{14}$. Sobre ello volveremos luego.

En otros pasajes de su tratado ( 38 y 76 ss.) nuestro autor discute extensamente sobre el origen de la poesía y afirma (38) que «de ningunos pueblos de España ha quedado tanta memoria de ser dados a la poesía como de los Turdetanos y Gallegos». Sobre los Turdetanos del sur de la península Sarmiento refiere el testimonio de Estrabón $(3.1 .6)^{15}$, quien afirma que tenían antiquísimas leyes puestas en verso, y al respecto Sarmiento cita (131), además de costumbres semejantes en pueblos americanos, un texto de los Problemas de Aristóteles (19.28) en el que se comenta la misma práctica entre los agatirsos, «pueblos de la Thracia o de la Sarmacia Europea, que tomaron su nombre de Agathyrso hijo de Hércules», polemizando de paso, con razón, contra quienes han malinterpretado el pasaje.

Más extensa, y más pertinente a nuestros efectos, es la sección que Fray Martín dedica a la ancestral vocación musical de los gallegos. Para ello parte también de un texto clásico, en concreto de un pasaje del libro tercero de La Guerra Púnica de Silio Itálico, en el cual se habla de los pueblos hispanos que acompañaron a Aníbal en su expedición a Italia. En los vv.334 ss., en efecto, Silio Itálico nos dice que «la rica Galicia envió su juventud experta en interpretar las fibras de las víctimas, el vuelo de las aves y los fuegos del cielo; unas veces en sus lenguas nativas gritan canciones bárbaras, otras golpean alternativamente la tierra con sus pies y se complacen en hacer resonar ritmicamente sus sonoros escudos》 (ad numerum resonas gaudentem plaudere caetras). Esta última palabra es la que más interesa a Sarmiento y aquélla de la que parte la discusión erudita que le lleva al mundo del mito. El escudo pequeño que designa la palabra caetra y que parece ser que usaban los gallegos como instrumento de percusión para acompañar sus cantos y bailes, recuerda a nuestro autor el armonioso empleo que hacían los míticos y también muy musicales Curetes de las armas de bronce que había inventado su madre Combe, apodada

\footnotetext{
${ }^{14}$ Nuestro autor admite la existencia de asentamientos griegos incluso al sur de Galicia en su opúsculo Sobre el origen de la lengua gallega, al que nos referiremos más adelante.

${ }^{15}$ La cita se da en traducción latina, pero el comentario de los problemas textuales del pasaje demuestra que Sarmiento se basa para su discusión en el original griego.
} 
por ello Calcis («Broncínea»). Es más, Sarmiento se hace eco de la hipótesis del erudito francés Fourmont, quien sostenía que precisamente los Curetes (Kourêtes) habían tomado su nombre a partir de este gusto por aporrear objetos metálicos, «pues -dice Fray Martín- el verbo curo en lengua céltica significa lo mismo que el verbo griego kroúo («golpear»)», y a la misma raíz pertenecerían caetra e incluso el nombre de la isla de Creta, uno de los emplazamientos míticos de los Curetes. Digamos nosotros (más de dos siglos después) que los especialistas actuales en la materia consideran el verbo galo curo como un préstamo del latín curare («preocuparse de»>»)corregir»>»)golpear»), mientras que el nombre de los Curetes se relaciona con el griego koûros «muchacho».

Volviendo a la línea argumental principal, si los hábitos bélico-musicales de los gallegos coinciden con los que practicaban los míticos Curetes, ¿cómo se produjo el contacto entre unos y otros?, ¿qué tienen que ver, en definitiva, los gallegos con los Curetes cretenses? Dos posibles explicaciones se le ocurren a nuestro buen fraile. En primer lugar, una explicación que parte del supuesto origen ibérico tanto de la palabra caetra (una posibilidad que admiten también los filólogos modernos) como de los míticos Curetes, a quienes Justino (en el libro 44 de su Epítome de las 'Historias Filipicas' de Pompeyo Trogo) ubica en Hispania: «los bosques de los Tartesios, en los cuales se dice que los Titanes hicieron la guerra contra los dioses, los habitaron los Curetes» ${ }^{16}$. Nuestro autor añade incluso (84) que «hasta hace poco eran todavía frecuentes en Madrid las procesiones con danzas muy parecidas a las de los Curetes, según los pinta Pezron».

Fray Martín Sarmiento es, sin embargo, partidario del origen egipcio, no ibérico, de los Curetes, de manera que propone otro itinerario para explicar la llegada de sus músicas y danzas a tierras gallegas. En su opinión, estaban ligadas al culto a Isis, que pasó de Egipto a Creta y al corazón del continente europeo, donde fue adoptado por germanos y celtas ${ }^{17}$,

\footnotetext{
${ }^{16}$ Sarmiento, por cierto, siempre muy atento a las cuestiones de crítica textual, comenta la propuesta de Gerardo Juan Vossius de leer en lugar de Curetes el nombre del pueblo de los Cunetes, habitantes del sudoeste peninsular, aunque argumenta que la mención de los Titanes habla en favor de la lección de los manuscritos.

${ }^{17}$ Cita al respecto un pasaje de la Germania de Tácito (9.2), donde se afirma que pars Suevorum Isidi sacrificat. Tácito también se inclina por suponer que este culto tan extendido en Germania es importado, e identificado con el culto a la diosa germánica Nertho.
} 
los cuales lo trajeron a su vez a la Península Ibérica «cuando la inundaron, y finalmente a los gallegos más boreales, en donde hicieron término de su transmigración». Por cierto que en el texto de Justino antes citado podría haber hallado Fray Martín un camino más corto para explicar la presencia en Galicia de costumbres documentadas también en la antigua Grecia, ya que en 44.3 leemos lo siguiente: «Por otra parte, los galaicos pretenden para sí un origen griego, ya que, después de terminada la guerra de Troya, dicen que Teucro, odioso a su padre Telamón por la muerte de su hermano Ayante, al no ser admitido en su reino, se retiró a Chipre y alli fundó la ciudad de Salamina, por el nombre de su antigua patria; de allí, después de conocer la noticia de la muerte de su padre, se encaminó a su patria, pero cuando Eurísaces, hijo de Ayante, le impidió la entrada, arribó a las costas de Hispania y ocupó el lugar donde está ahora Cartago Nova, y después pasó a Galicia, donde se estableció y dio nombre a aquel pueblo». Teucro es mencionado por Sarmiento en otra obra, su Catálogo de voces vulgares y en especial de voces gallegas de diferentes vegetables ${ }^{18}$, cuando identifica la planta seixebra $\left(\mathrm{n}^{\circ} 1567\right)$, la saxífraga castellana, con el teucrium del botánico francés Tournefort, así llamada por haber sido empleada por Teucro en un sacrificio.

Las referencias mitológicas al servicio de la etimología en las Memorias para la historia de la poesía española y poetas españoles no se agotan con Curetes y gallegos. Algo más adelante (en el parágrafo 128) nuestro autor se hace eco del mito a partir del cual se interpreta el nombre de la isla griega de Delos como «la visible, la manifiesta», que conocemos sobre todo por el Himno a Delos de Calímaco; y una nueva explicación tomada de la mitología grecolatina se propone (527 ss.) para el nombre del protagonista del largo Romance del moro Calaínos. Calaínos es en el poema un capitán árabe que, por complacer a su dama, la hija de su señor Almanzor, marcha a Francia a combatir nada menos que contra los Pares de Francia, Oliveros, Reinaldos de Montalbán y Roldán, con la lógica consecuencia de que acaba muriendo «por manos del esforzado, el buen paladín Roldán». El romance parece que no era muy del agrado de Fray Martín, que lo tacha, creo que en esta ocasión injustamente, de «viejas y chabacanas coplas», y además tampoco parece muy complacido con que

${ }^{18}$ Edición y estudio de J.L. PENSADO, Salamanca 1986. 
un árabe se llame Calaínos: «Y a la verdad, el nombre Calaínos dudo que sea arábigo; y me parece más verisímil sea griego, o tomado de Calais hermano de Zethes y entrambos hijos de Bóreas y caballeros andantes, o acaso del héroe amoroso Calais» (al que conoce por una cita tomada de la Bibliotheca Graeca de Fabricius, según la cual Praxila de Sición dedicó a un tal Calais un poema quejándose de la inconstancia de su amor). En todo caso, creo que el propio Sarmiento tampoco debía de tenerlas todas consigo cuando añade que «esto sólo se apunta para que, no sabiéndose el verdadero origen, quede lugar a la conjetura».

Finalmente, frecuentes observaciones sobre etimologías se encuentran también en la obra Catálogo de voces y frases de la lengua gallega ${ }^{19}$, y de cuando en cuando nos tropezamos con hechos y personajes del mundo mítico y del panteón grecolatino. Así, Fray Martín identifica el árbol denominado lamagueiro (134v) con el «loto de Homero» (en los diccionarios que hemos consultado se le hace equivalente al chopo o al almez); Corpo Santo (129v-130r) llaman en Portugal al Fuego de San Telmo, también denominado ya desde la Antigüedad Cástor y Pólux; en Orense llaman a la Santa Compaña As Xans (163), una denominación que nuestro autor pone en relación con la palabra xanas con la que «designan en Asturias a las moras encantadas de las fuentes», y sugiere su origen etimológico en el nombre del dios Jano o de $\mathrm{Fauno}^{20}$; ya mucha mayor imaginación se necesita para admitir la relación etimológica entre el Tereo del mito griego, que acabó transformado en abubilla, y la denominación Dona Theresa con que el ave era al parecer designada en algunas comarcas gallegas (182). Por último, en su glosa de la palabra barcal (artesa en la que se ponen las vasijas de medir el vino para recoger el que se cae) recuerda Sarmiento que la muy rara voz latina bacar, -aris, que designa un tipo de vaso y en especial un orinal, ya es puesta en relación en las Etimologías de San Isidoro (20.5.4) con el nombre del dios Baco, una etimología que, nos dice Sarmiento, defiende Gerardo Juan Vossius en su Etymologicon Linguae Latinae, ya que el bacar servía para vino ${ }^{21}$.

\footnotetext{
${ }^{19}$ Edición y estudio de J.L. PENSADO, Salamanca 1973.

${ }^{20}$ Xana deriva en realidad del nombre latino de otra divinidad pagana, Diana, la diosa de la naturaleza salvaje.

${ }^{21}$ Esta etimología ha sido también defendida por J. ÁLVAREZ DELGADO, «Purpura Gaetulica», Emerita 14 (1946), pp. 123-124.
} 
Frente al uso «filológico» que hemos considerado hasta aquí, el empleo que podríamos denominar «literario» de la mitología grecolatina es más escaso en la obra de Fray Martín Sarmiento y se concentra especialmente en su epistolario (aunque tampoco falta en otros escritos). Con frecuencia este tipo de alusiones a personajes míticos se encuentra también en discusiones eruditas como ilustración de los argumentos de nuestro autor o de los problemas con los que se tropieza quien lleva a cabo una investigación científica. Así, en su opúsculo Sobre el origen de la lengua gallega (repleto, por cierto, de sensatísimas observaciones metodológicas y de pormenor $)^{22}$ recurre a la historia mítica de Teseo y Ariadna para ilustrar el intrincado laberinto con el que se topa quien se dispone a abordar el estudio del problema que da título a la obra (p. 19): «No se puede hablar del origen de la lengua gallega sin enredarse en el origen de las otras lenguas o en el laberinto non creditorum, que es más enredoso e inextricable, por no haberse hallado hasta ahora ninguna Ariadne que les comunicase el hilo». Y enseguida vuelve a servirse del mito para arremeter contra quienes, por chauvinismo nacionalista al hablar de las lenguas, dicen unos disparates más que medianos: «He notado que quienes quieren apurar el origen de alguna lengua, hacen lo que algunos genealogistas alquilados, que quieren apurar hasta el huevo de Leda el origen de alguna familia conocidamente noble. Y de lo que finalmente unos y otros persuaden a los que sólo buscan la verdad, es de que han dado con los huevos en la ceniza de la nada y que todo es una ficción bien o mal parada»; y continúa: «A sostener esos disparates de la fantasía concurren muchas cosas. Para ensalzar el origen de ésta o de la otra lengua ha concurrido la nimia pasión nacional... como la del P. Pezron y otros franceses por la céltica... Toda la lengua gallega vulgar y la que consta en los manuscritos antiguos... es una varia inflexión de las voces latinas, y es error creerla dialecto de la lengua castellana, ni antigua ni moderna».

Sobre el mismo tema vuelve nuestro autor en otra obrita muy interesante, Origen y formación de las lenguas bárbaras ${ }^{23}$, donde comenta las

${ }^{22}$ Edición de J.L. PENSADO en Opúsculos lingüísticos gallegos del siglo XVIII, Vigo 1974, pp. 17-41. Escritos filológicos del Padre Sarmiento están recogidos en el Boletín de la RAE 15, 1928, pp. 670-674; 16, 1929, pp. 244-255 y 366-382; 17, 1930, pp. 275-290, 571-592 y 721-742; 18, 1931, pp. 118-135.

${ }^{23}$ Boletín de la RAE 16, 1929, pp. 244-255. 
pintorescas ideas (visionario y fanático son los calificativos que dedica Fray Martín a su autor) expuestas en el libro Antropoglottogonia de Juan Pedro Erico, publicado en Venecia en 1697. Sostenía Erico que todas las lenguas tienen su origen en la lengua griega y que Adán fue el primero en pronunciar la omega, Eva la ípsilon, Caín la épsilon y Abel la iota, «y así forma en el paraíso las vocales, como principios de la lengua humana» (claro que más descaminado aún iba Juan Goropio Becano, que «llegó al desatino de afirmar que su lengua flamenca era la primera de todas»). En su crítica de esta peculiar hipótesis, Sarmiento recurre al mito, esta vez utilizado como argumento histórico, alegando lo siguiente: «Entonces [cuando se produjo el diluvio de tiempos de Deucalión, que se data en 1529 a.C.] se inundó toda Grecia, y toda se redujo a solas dos personas, Deucalión y Pyrrha, marido y mujer. ¿En dónde estaba entonces la lengua griega? Entre la confusión y el diluvio de Ogiges mediaron cuatrocientos y treinta y ocho años, tiempo sobrado para formar muchas lenguas naturales y bárbaras, según mi sistema... En tiempo de Deucalión ${ }^{24}$ ya consta de la Escritura que los egipcios eran doctos en todo género de sabiduría. Esto no pudo ser sin que los egipcios hubiesen pasado por una lengua natural, por una lengua artificial y por una lengua culta y pulida después que los descendientes de Cam se esparcieron por Egipto. Mil años después del diluvio de Deucalión ya la Grecia estaba civilizada y, no obstante, los egipcios aún miraban a los griegos como a niños y rapaces en las ciencias».

Durante la Ilustración los sabios se apasionaron con el proyecto de crear una lengua universal que sirviese de vía de comunicación para la Humanidad toda. El Padre Sarmiento no dejó naturalmente de sentirse atraído por esta idea, a la que dedicó su opúsculo Tentativa para una lengua general, compuesto hacia $1760^{25}$. No obstante, sus conocimientos filológicos, en especial la claridad de sus ideas a propósito de la evolución de las lenguas y de las características fonéticas de cada una, lo llevó a considerar una quimera el intento de crear una lengua única, y a proponer, en consecuencia, un proyecto menos ambicioso y más realista: «Es quimera que todas las naciones del mundo puedan concordar en pronunciar tales y tales letras de un mismo modo; aun dentro de una nación

${ }^{24}$ Se le hace contemporáneo de Moisés.

${ }^{25}$ Boletín de la RAE 16, 1929, pp. 366-382. 
sucede esto entre diferentes territorios. A diez leguas que disten entre sí estos países, aun usando de la misma lengua, no concuerdan en la pronunciación, no sólo de una dicción, pero de tal y tal letras, ni del acento o tonillo [p. 373]... No ya pienso en lengua universal, sino en una lengua general que abrace las cosas que Dios ha criado, dejando las cosas que el capricho humano o fabricó o fingió [p. 376]». Lo que propone Sarmiento es, pues, un proyecto menos ambicioso y más realista, no ya la creación de una utópica lengua universal, sino de una nomenclatura de validez universal para los objetos reales («en especial para la historia natural en sus tres reinos», precisa nuestro autor, aludiendo a lo que es su propósito principal, la creación de una lengua única que sirva de comunicación universal para los estudios científicos), dotándola además de unas características fonéticas tales que las palabras puedan ser pronunciadas por gentes de todas las naciones. Sarmiento (siguiendo ideas anticipadas por autores anteriores, especialmente por el sabio jesuíta alemán Athanasius Kirchner) concibe la organización de esa lengua general como una especie de cadena en la que las cosas naturales se ordenan de manera similar a la serie natural de los números «en la jerarquía y gradación en que Dios las ha colocado, desde los ángeles hasta la más mínima zurrapa de la materia. Y esta serie se podrá considerar como una cadena comenzando de Dios hasta la materia, o desde la materia hasta Dios... Cualquier erudito podrá escoger y numerar a su modo los eslabones u objetos que se han de engarzar en esta cadena o como rosario». $\mathrm{Y}$ en este punto volvemos a encontrarnos con el mito griego, en este caso recogiendo las interpretaciones alegóricas de los poemas homéricos, frecuentes desde la Antigüedad misma: "Acaso Homero, en nombre de los antiguos, aludió a esta cadena cuando fingió que Júpiter había suspendido a Juno en el aire o éter, colgada en una cadena de oro con dos yunques en los pies y atadas las manos con unas vendas de oro ${ }^{26}$, o cuando el mismo Homero fingió que desde Júpiter hasta la tierra pendía una cadena de oro, y que tirando de ella todos los dioses y diosas con todas sus fuerzas, jamás pudieron mover a Júpiter ${ }^{27}$. Esa cadena representaría la concatenación de las cosas que Dios había criado con número, peso y medida».

\footnotetext{
${ }^{26}$ Ilíada 15.14 ss.

${ }^{27}$ Iliada 8.8 ss.
} 
No sólo en lo referente a las cuestiones filológicas, sino en muchos otros ámbitos del saber, Fray Martín Sarmiento siguió siempre con gran atención los nuevos avances científicos, emitiendo sobre ellos un juicio generalmente atinado, aunque por supuesto no faltaron ocasiones en las que no acertó a vislumbrar la importancia de los nuevos descubrimientos. Un buen ejemplo de ello lo tenemos en la epístola $\mathrm{n}^{\circ} 135$ (escrita en Madrid el 22 de Junio de 1752 y dirigida al Duque de Medina Sidonia). En ella considera con escepticismo y comenta con su punto de ironía las investigaciones de un bostoniano llamado Benjamín Franklin, que decía haber ideado un artilugio para evitar que los rayos destrozaran casas y barcos, consistente en unas barras de hierro terminadas en punta y unidas entre sí y con la tierra o con el agua por medio de conductores metálicos (a pesar de su escepticismo, nuestro autor demuestra conocer bien el mecanismo del invento). En su crítica, Sarmiento recurre (con una cita virgiliana, de Eneida 6.586) al mito de Salmoneo, que quiso imitar el aparato eléctrico de Zeus construyendo un camino con pavimento de bronce y lanzándose por él sobre un carro con ruedas metálicas del que arrastraban cadenas, mientras arrojaba a diestro y siniestro antorchas encendidas que pretendían ridículamente ser rayos; Fray Martín se expresa en los siguientes términos: "Yo me temo que los ingleses, según van, han de venir a parar en lo que Salmoneo, hijo de Eolo, que por querer imitar los truenos y los rayos de Júpiter, dum flammas Iovis, sonitus imitatur $O l y m p i^{28}$, lo mató Júpiter con un rayo y le precipitó en los infiernos. Mañana saldrá otro diciendo que todo el infierno es una máquina eléctrica y que, agitado el fuego central, resultarán acá arriba por la electricidad relámpagos, truenos, rayos, sapos y culebras...y cátate que ya el Etna y el Vesubio son dos máquinas eléctricas que siempre están con la boca abierta». Sobre el tema de los rayos vuelve Sarmiento en la epístola $n^{\circ} 142$, casi cuatro años posterior, y también en este caso recurre a la cita de un pasaje de la Eneida (2.684) en el que se describe el prodigioso rayo de luz que apareció sobre la cabeza de Julo: «De aquella luz o fuego fatuo que Virgilio finge que se apareció sobre la mollera de Julo, hijo de Eneas, dice que se vio lambere flamma comas et circum tempora pasci $i^{29}$ ».

\footnotetext{
28 "Mientras trataba de imitar las llamas de Júpiter y el fragor del Olimpo».

${ }^{29}$ «Lamer una llama sus cabellos y posarse en torno a sus sienes».
} 
Ya no Virgilio, sino Ovidio, es la fuente explícita de otras dos referencias mitológicas de las epístolas de Sarmiento. En la n 175 (dirigida desde Madrid al Duque de Medina Sidonia el 13 de Septiembre de 1765) se lamenta del abandono del campo español, que considera una de las causas del atraso económico del país. Se remonta a la terrible peste que asoló Europa y Asia en 1348 y que dejó España despoblada, de manera que «en muchas parroquias sólo quedaron las torres y las que llaman iglesias rurales. Esas iglesias o, al menos, esas torres, están voceando lo que Aeaco dijo en Ovidio ${ }^{30}$ a su padre Júpiter: aut mihi redde meos, aut me quoque conde sepulcro ${ }^{31}$. Había aniquilado una peste todos los vecinos de su isla y sólo había quedado el dicho Aeaco. Por eso apostrofó a Júpiter a que o le restituyese a sus vasallos, o que a él mismo lo sepultase con ellos... Eso mismo están clamando las iglesias y torres rurales: o restitúyansenos nuestros parroquianos o mándese que nos sepulten y abismen con ellos, para que no quede memoria de la peste ni de la desidia en no haber repoblado esas parroquias. La peste duró algunos años, pero la desidia ya pasa de 400 años que dura».

También citas ovidianas acompañan dos referencias al mito de Aracne. En la carta $n^{\circ} 157$ (18 de Octubre de 1759) se parafrasea un pasaje de las Metamorfosis (6.5 ss.) a propósito del comentario de Sarmiento a un erudito estudio en el que Monsieur Reaumur demostraba la poca productividad que tendría la cría de arañas para la industria textil, ya que para obtener una libra de seda sería preciso alimentar 55.296 arañas gordas o 663.552 si son de las pequeñas.

Aracne, junto a una de las Parcas, Láquesis, reaparece en la carta $\mathrm{n}^{\circ}$ 174 (7 de Septiembre de 1765), donde nuestro ya anciano fraile afirma que su salud es buena «acaso porque no me muevo de mi rincón, en donde, como la araña, o estoy papando moscas o estoy tejiendo y tirando líneas, o estoy meditando en que todas las felicidades humanas están pendientes de un hilo. Eso ya lo había dicho Ovidio ${ }^{32}$ : omnia sunt hominum tenui pendentia filo».

\footnotetext{
${ }^{30}$ Metamorfosis 7.618 .

${ }^{31}$ "O devuélveme a los mios, o ocúltame a mi también en una sepultura».

${ }^{32}$ Cartas desde el Ponto 4.3.35: «todos los asuntos humanos penden de un delgado hilo».
}

«CUADERNOS DE ESTUDIOS GALLEGOS», Tomo XLVIII, Fascículo 114, Santiago 2001. 
Este texto es buen reflejo de la curiosa personalidad de un hombre que vivió activa, incluso fervientemente, su tiempo desde su voluntaria reclusión en su celda madrileña, acompañado de sus libros, a quienes también dedica una referencia mitológica en su carta 150 (8-5-1758): «y como usted no ignora, la lluvia no habla conmigo ni me incomoda, aunque tal vez hable con mis libros, metiéndose por las goteras, al modo que Júpiter Pluvial se metió por las goteras de la torre de Dánae, bajando en lluvia de oro». 